\title{
Prediksi Persediaan Bahan Baku untuk Produksi Percetakan Menggunakan Metode Asosiasi
}

\author{
Agus Juniadi $^{1}$, Alif Rahman ${ }^{2}$, Yunita ${ }^{3}$ \\ ${ }^{1}$ Universitas Bina Sarana Informatika \\ e-mail:agus.ajs@bsi.ac.id \\ ${ }^{2}$ Sekolah Tinggi Manajemen Informatika dan Komputer Nusa Mandiri \\ e-mail: alifrahman1212@gmail.com, \\ ${ }^{3}$ Sekolah Tinggi Manajemen Informatika dan Komputer Nusa Mandiri \\ yunita.ynt@nusamandiri.ac.id
}

\begin{abstract}
Abstrak - Penggunaan teknologi dibidang industri percetakan offset printing saat ini membuat pengguna dapat lebih cepat mendapatkan hasil produksi, keunggulan lain dari industri percetakan offset adalah printing kualitas cetak tinggi, warna cetakan konsisten dan biaya murah untuk cetak volume besar. Industri percetakan offset printing adalah salah industri yang memiliki pemesanan bahan baku yang paling sering, hal ini disebabkan oleh pola konsumen yang memesan produk lebih dari satu jenis kertas. Oleh karena itu ketidak tersedia bahan baku bisa menyebabkan terkendala nya order yang di dapat. Dengan menggunakan metode asosiasi ini dapat diketahui jumlah bahan baku kertas yang diperlukan untuk menyelesaikan suatu produk di masa yang akan datang sehingga perusahaan dapat mengoptimalkan persediaan bahan baku yang diperlukan agar jumlah persediaan tidak terlalu banyak tetapi juga tidak terlalu sedikit. Dalam penelitian ini support yang di pakai mempunyai ambang batas lebih dari $20 \%$ dan minimum confidencen $30 \%$. Dengan hasil tersebut dapat lebih optimal dalam pemesanan bahan baku kertas berikutnya dan dapat mengatur tempat penyimpanan dengan baik.
\end{abstract}

Kata Kunci: Data Mining, Asosiasi, Bahan Baku

\begin{abstract}
The use of technology in the offset printing industry is now making it faster for users to get production results. Another advantage of the offset printing industry is high quality printing, consistent color printing and low cost for large volume printing. The offset printing industry is one of the industries that have the most frequent ordering of raw materials, this is due to the pattern of consumers who order more than one type of paper. Therefore, the unavailability of raw materials can cause the order to be constrained. By using this association method, it can be seen the amount of paper raw material needed to complete a product in the future so that the company can optimize the supply of raw materials needed so that the amount of inventory is not too much but not too little. In this study the support used has a threshold of more than $20 \%$ and a minimum confidence $30 \%$. With these results can be optimized in the subsequent ordering of raw materials for paper and can manage the storage properly.
\end{abstract}

Keywords: Data Mining, Association, Raw Material

\section{PENDAHULUAN}

Penggunaan teknologi dibidang industri percetakan offset saat ini membuat pengguna dapat lebih cepat mendapatkan hasil produksi, keunggulan lain dari industri percetakan offset adalah printing kualitas cetak tinggi, warna cetakan konsisten dan biaya murah untuk cetak volume besar. Beberapa produk yang dihasilkan industri offset printing adalah buku, koran, majalah dan paper bag. Produk yang dihasilkan menggunakan bahan baku utama berupa kertas dan tinta. Bahan baku adalah bahan yang dipergunakan dalam proses produksi pada periode yang bersangkutan.
Bahan baku kertas adalah material yang akan diteliti dalam penelitian ini, karena merupakan bahan baku utama yang paling banyak digunakan dalam produksi. Pemesanan bahan baku kertas harus berdasarkan kebutuhan yang paling ekonomis sehingga tidak menimbulkan kerugian dan penumpukan bahan baku untuk jenis yang jarang digunakan. Pembelian kertas selalu konstan setiap awal bulan sebanyak 100.000 $\mathrm{Kg}$ untuk berbagai jenis kertas. Selama ini pembelian dan pemesanan bahan baku berdasarkan perkiraan atau prediksi pemilik, sehingga sering mengalami penumpukan maupun kekurangan bahan baku. 
Industri percetakan offset adalah salah industri yang memiliki pemesanan bahan baku yang paling sering, hal ini disebabkan oleh pola konsumen yang memesan produk lebih dari satu jenis kertas. Hal ini juga menyebabkan perusahaan harus menyiapkan seluruh jenis kertas, penyimpanan bahan baku untuk seluruh jenis kertas juga menjadi sebuah kendala dikarenakan keterbatasan tempat penyimpanan bahan baku sementara. Proses produksi yang didasarkan pada kebutuhan konsumen untuk produk yang dipesan dan ketersediaan bahan baku (Haryana et al., 2017).

Perkembangan teknologi di bidang pengelolaan data, data mining dan data historis dapat digunakan untuk mendukung kegiatan menganalisa data penjualan dan memprediksi jumlah bahan baku produksi.(Asa Verano, 2016) Semoga dengan metode asosiasi ini dapat diketahui jumlah bahan baku kertas yang diperlukan untuk menyelesaikan suatu produk di masa yang akan datang sehingga perusahaan dapat mengoptimalkan persediaan bahan baku yang diperlukan agar jumlah persediaan tidak terlalu banyak tetapi juga tidak terlalu sedikit. Sehingga perusahaan dapat mengatasi permasalahan dalam memutuskan jadwal pembelian bahan baku yang harus dibuat dalam rangka memenuhi permintaan konsumen.(Irawan \& Syaicu, 2017).

\section{Data Mining}

Data mining adalah melakukan analisis data atau statistik pada set data seringkali besar yang telah diperoleh dari berbagai sumber yang di dapat.(Nisbet et al., 2017) Data mining merupakan suatu kegiatan yang berguna dalam pemakaian data, pengumpulan data, histori penggunaan yang berguna untuk menemukan keteraturan, pola dan hubungan set data berukuran besar.(Elisa, 2018)

Data mining dapat mencakup beberapa hal seperti pengelompokan dan klasifikasi, pemilihan fitur, dan ekstraksi fitur dan pembelajaran mesin teknik seperti metode pohon keputusan, model Markov tersembunyi, karya jaringan syaraf tiruan, dan mesin vektor pendukung.(Yang, 2019) Data mining merupakan topik praktis dan melibatkan pembelajaran dalam arti praktis, bukan teoretis tetapi lebih tertarik pada teknik untuk menemukan pola dalam data dan pola yang memberikan wawasan atau memungkinkan pengambilan keputusan yang cepat dan akurat.(Witten et al., 2016)

\section{Asosiasi}

Asosiasi merupakan metode yang bertujuan untuk mencari suatu pola yang sering muncul di dalam beberapa transaksi yang dilakukan, setiap transaksi yang di lakukan itu terdiri dari beberapa item jadi metode ini merekomendasikan melalui penemuan pola antara item dalam beberapa transaksi yang terjadi.(Kadafi, 2019)
Asosiasi merupakan salah satu teknik dari data mining yang merupakan dasar dari berbagai teknik data mining lainnya. Pola frekuensi tinggi merupakan salah satu yang sering digunakan penelitian karena dapat menghasilkan algoritma yang efisien. (Wahyuning et al., 2017) Aturan asosiasi juga memberikan pengetahuan kepada pengguna saat mereka meringkas secara efektif data, sambil mengungkap hubungan tersembunyi (di antara item) yang memegang data.(Aris Gkoulalas-Divanis, 2010)

Berikut merupakan rumus support dan confidence: Untuk mencari nilai support kandidat 1 item-set menggunakan rumus:

$$
\begin{aligned}
& \text { Support }=P(A) \\
& =\frac{\text { jumlah transaksi mengandung } A}{\text { total transaksi }} \times 100 \%
\end{aligned}
$$

Untuk mencari nilai support kandidat 2 item-set menggunakan rumus:

$$
\begin{aligned}
& \text { Support }=P(A \cap B) \\
& =\frac{\text { jumlah transaksi mengandung } A \text { dan } B}{\text { total transaksi }} \times 100 \%
\end{aligned}
$$

Mencari nilai minimum confidence menggunakan rumus:

$$
\begin{aligned}
& \text { Confidence }=P(B \mid A)=\frac{P(A \cap B)}{P(A)} \\
& =\frac{\text { jumlah transaksi mengandung } A \text { dan } B}{\text { transaksi } A} \times 100 \%
\end{aligned}
$$

Minimum support adalah parameter yang digunakan dalam menentukan pola dalam data mining untuk menemukan statistik dari pola-pola yang signifikan. Confidence, merupakan sebuah parameter yang berguna untuk menunjukkan hubungan antar dua item secara conditional.(Junaidi, 2019)

\section{METODOLOGI PENELITIAN}

Secara umum tahap-tahap yang dilakukan dalam penelitian ini meliputi tahap seperti pada gambar 1 .

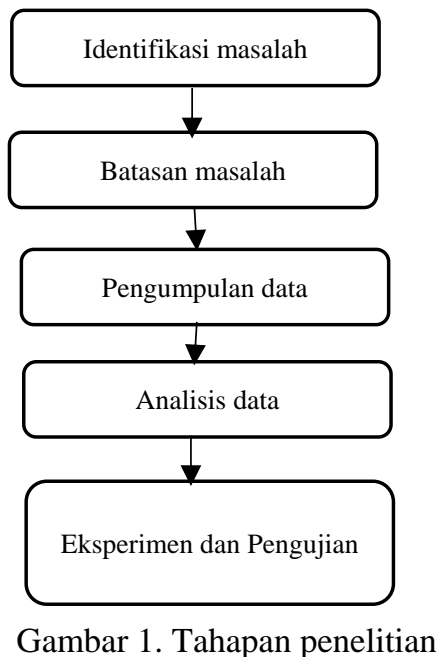




\section{Identifikasi Masalah}

Tahapan ini berfungsi untuk mengidentifikasi masalah yang dilakukan peneliti dalam menentukan langkah-langkah selanjutnya. Masalah yang teridentifikasi di PT. Aliansi Temprina Nyata Grafika adalah masalah yang berkaitan dengan stok bahan baku kertas.

2. Batasan Masalah

Dalam penelitian ini peneliti memberikan batasan permasalahan agar permasalahan yang diteliti lebih fokus untuk tujuan yang diinginkan. Batasan masalah yang digunakan dalam penelitian ini adalah bahan baku kertas.

3. Pengumpulan Data

Pengumpulan data yang dilakukan dalam penelitian ini yaitu di PT. Aliansi Temprina Nyata Grafika pada bagian bahan baku yang di ambil sampel data yaitu kertas.

4. Analisis Data
Pada penelitian ini analisis data yang dilakukan yaitu analisis terhadap data pemakaian kertas. Data yang diperoleh dari bagian gudang bahan baku, sebelum diolah data hasil pemakaian akan di ubah ke dalam format data tabular dan kemudian dicari support dan confidence.

5. Eksperimen dan Pengujian dengan RapidMiner Tahapan selanjutnya melakukan eksperimen dan pengujian dengan menggunakan software RapidMiner.

\section{HASIL DAN PEMBAHASAN}

Hasil dari pengumpulan data pemakaian bahan baku kertas pada PT. Aliansi Temprina Nyata Grafika selama satu bulan didapatkan data yang dapat ditampilkan dalam tabel 1 .

Tabel 1. Data Pemakaian Kertas

\begin{tabular}{|c|c|c|c|c|c|c|c|c|c|}
\hline $\begin{array}{c}\text { Tgl } \\
\text { Pemakaian }\end{array}$ & $\begin{array}{c}\text { Adog } \\
45 \mathrm{gr} \\
128 \mathrm{~cm} \\
\text { Roll /kg }\end{array}$ & $\begin{array}{c}\text { Adog } \\
45 \mathrm{gr} \\
138 \mathrm{~cm} \\
\text { Roll } / \mathrm{kg}\end{array}$ & $\begin{array}{c}\text { Adog } \\
45 \mathrm{gr} \\
64 \mathrm{~cm} \\
\text { Roll /kg }\end{array}$ & $\begin{array}{c}\text { Adog } \\
45 \mathrm{gr} \\
69 \mathrm{~cm} \\
\text { Roll } / \mathrm{kg}\end{array}$ & $\begin{array}{c}48.8 \mathrm{gr} \\
144 \mathrm{~cm} \\
\text { Roll } / \mathrm{kg}\end{array}$ & $\begin{array}{c}48.8 \mathrm{gr} \\
152 \\
\mathrm{~cm} \\
\text { Roll /kg }\end{array}$ & $\begin{array}{c}48.8 \mathrm{gr} \\
76 \mathrm{~cm} \\
\text { Roll /kg }\end{array}$ & $\begin{array}{c}\text { Sp 60gr } \\
156 \\
\mathrm{~cm} \\
\text { Roll /Kg }\end{array}$ & $\begin{array}{c}\text { Sp } 60 \mathrm{gr} \\
78 \mathrm{~cm} \\
\mathrm{Roll} \\
/ \mathrm{kg}\end{array}$ \\
\hline 1 & $2 / 1500$ & - & - & - & $1 / 675$ & - & $1 / 460$ & - & - \\
\hline 2 & - & $3 / 2400$ & - & - & - & - & - & - & - \\
\hline 3 & $4 / 3000$ & $1 / 800$ & & - & & - & - & $1 / 1050$ & $1 / 550$ \\
\hline 4 & $5 / 3750$ & $2 / 1600$ & - & - & $2 / 1350$ & - & $3 / 1380$ & - & - \\
\hline 5 & - & - & - & - & - & - & - & - & - \\
\hline 6 & $2 / 1500$ & $2 / 1600$ & - & - & - & - & - & - & - \\
\hline 7 & $3 / 2250$ & $2 / 1600$ & - & - & - & $1 / 930$ & - & - & - \\
\hline 8 & $3 / 2250$ & $2 / 1600$ & - & & $1 / 675$ & - & - & $3 / 3150$ & - \\
\hline 9 & $3 / 1500$ & - & - & - & & - & - & - & - \\
\hline 10 & $2 / 1500$ & $2 / 1600$ & - & - & $1 / 675$ & - & - & $1 / 1050$ & $1 / 550$ \\
\hline 11 & $3 / 2250$ & $1 / 800$ & - & - & $1 / 675$ & - & $3 / 1380$ & - & - \\
\hline$\ldots$ & $\ldots$ & $\ldots$ & $\ldots$ & $\ldots$ & $\ldots$ & $\ldots$ & $\ldots$ & $\ldots$ & $\ldots$ \\
\hline 21 & $3 / 2250$ & $2 / 1600$ & - & $1 / 440$ & $1 / 675$ & $1 / 930$ & - & - & - \\
\hline 22 & & $2 / 1600$ & - & - & & - & - & - & - \\
\hline 23 & $3 / 2250$ & $2 / 1600$ & - & - & $1 / 675$ & - & - & $3 / 3150$ & $1 / 550$ \\
\hline 24 & $3 / 2250$ & - & $1 / 375$ & - & - & - & - & - & - \\
\hline 25 & $3 / 2250$ & $2 / 1600$ & - & - & $1 / 675$ & - & $4 / 1840$ & - & - \\
\hline 26 & $5 / 3750$ & - & - & - & $1 / 675$ & $1 / 930$ & - & - & - \\
\hline 27 & - & - & $1 / 375$ & - & - & - & - & - & - \\
\hline 28 & $3 / 2250$ & $2 / 1600$ & - & - & - & - & - & $1 / 1050$ & - \\
\hline 29 & $1 / 750$ & & - & & $1 / 675$ & $1 / 930$ & - & - & - \\
\hline 30 & $5 / 3750$ & $2 / 1600$ & - & $1 / 440$ & $1 / 675$ & - & $3 / 1380$ & - & - \\
\hline 31 & - & $3 / 2400$ & - & - & - & $2 / 1860$ & - & - & - \\
\hline Total & $\begin{array}{c}80 / 6000 \\
0\end{array}$ & $\begin{array}{c}42 / 3360 \\
0\end{array}$ & $4 / 1500$ & $3 / 1320$ & $\begin{array}{c}16 / 1080 \\
0\end{array}$ & $8 / 7440$ & $18 / 8280$ & $10 / 10500$ & $4 / 2200$ \\
\hline
\end{tabular}

Sumber: PT. Aliansi Temprina Nyata Grafika, 2020

Dalam tabel 1 baris judul menunjukkan kelompok barang dan baris selanjutnya adalah jumlah pemakaian kertas, sedangkan kolom pertama berisi tanggal pemakaian kertas. Tahapan selanjutnya untuk dapat memasukkan data pada RapidMiner maka format data pada Tabel 1 yang berupa numerik diubah menjadi format binominal yang berisi angka 1 untuk transaksi yang artinya pemakaian kertas dan angka 0 
untuk transaksi yang tidak memakai kertas, sehingga menjadi seperti tampilan pada tabel 2 .

Tabel 2. Data Pemakaian Kertas Format Binominal

\begin{tabular}{|c|c|c|c|c|c|c|c|c|c|}
\hline $\begin{array}{c}\text { Tgl } \\
\text { Pemakaian }\end{array}$ & $\begin{array}{c}\text { Adog } 45 \mathrm{gr} \\
128 \mathrm{~cm}\end{array}$ & $\begin{array}{c}\text { Adog } \\
45 \mathrm{gr} \\
138 \mathrm{~cm}\end{array}$ & $\begin{array}{l}\text { Adog } \\
45 \mathrm{gr} \\
64 \mathrm{~cm}\end{array}$ & $\begin{array}{l}\text { Adog } \\
45 \mathrm{gr} \\
69 \mathrm{~cm}\end{array}$ & $\begin{array}{c}48.8 \mathrm{gr} \\
144 \mathrm{~cm}\end{array}$ & $\begin{array}{c}48.8 \mathrm{gr} \\
152 \\
\mathrm{~cm}\end{array}$ & $\begin{array}{c}48.8 \mathrm{gr} \\
76 \mathrm{~cm}\end{array}$ & $\begin{array}{c}\mathrm{Sp} 60 \mathrm{gr} \\
156 \\
\mathrm{~cm}\end{array}$ & $\begin{array}{c}\text { Sp } 60 \text { gr } \\
78 \mathrm{~cm}\end{array}$ \\
\hline 1 & 1 & 0 & 0 & 0 & 1 & 0 & 1 & 0 & 0 \\
\hline 2 & 0 & 1 & 0 & 0 & 0 & 0 & 0 & 0 & 0 \\
\hline 3 & 1 & 1 & 0 & 0 & 0 & 0 & 0 & 1 & 1 \\
\hline 4 & 1 & 1 & 0 & 0 & 1 & 0 & 1 & 0 & 0 \\
\hline 5 & 0 & 0 & 0 & 0 & 0 & 0 & 0 & 0 & 0 \\
\hline 6 & 1 & 1 & 0 & 0 & 0 & 0 & 0 & 0 & 0 \\
\hline 7 & 1 & 1 & 0 & 0 & 0 & 1 & 0 & 0 & 0 \\
\hline 8 & 1 & 1 & 0 & 0 & 1 & 0 & 0 & 1 & 0 \\
\hline 9 & 1 & 0 & 0 & 0 & 0 & 0 & 0 & 0 & 0 \\
\hline 10 & 1 & 1 & 0 & 0 & 1 & 0 & 0 & 1 & 1 \\
\hline 11 & 1 & 1 & 0 & 0 & 1 & 0 & 1 & 0 & 0 \\
\hline 12 & 1 & 1 & 0 & 0 & 0 & 0 & 0 & 0 & 0 \\
\hline 13 & 1 & 1 & 0 & 0 & 0 & 0 & 0 & 0 & 0 \\
\hline 14 & 1 & 1 & 0 & 0 & 1 & 1 & 0 & 0 & 0 \\
\hline 15 & 1 & 1 & 0 & 1 & 0 & 1 & 0 & 0 & 0 \\
\hline 16 & 1 & 0 & 1 & 0 & 1 & 0 & 0 & 0 & 0 \\
\hline 17 & 1 & 0 & 0 & 0 & 0 & 0 & 1 & 1 & 1 \\
\hline 18 & 1 & 1 & 0 & 0 & 1 & 0 & 1 & 0 & 0 \\
\hline 19 & 1 & 1 & 0 & 0 & 0 & 0 & 1 & 0 & 0 \\
\hline 20 & 1 & 1 & 1 & 0 & 1 & 0 & 0 & 0 & 0 \\
\hline 21 & 1 & 1 & 0 & 1 & 1 & 1 & 0 & 0 & 0 \\
\hline 22 & 0 & 1 & 0 & 0 & 0 & 0 & 0 & 0 & 0 \\
\hline 23 & 1 & 1 & 0 & 0 & 1 & 0 & 0 & 1 & 1 \\
\hline 24 & 1 & 0 & 1 & 0 & 0 & 0 & 0 & 0 & 0 \\
\hline 25 & 1 & 1 & 0 & 0 & 1 & 0 & 1 & 0 & 0 \\
\hline 26 & 1 & 0 & 0 & 0 & 1 & 1 & 0 & 0 & 0 \\
\hline 27 & 0 & 0 & 1 & 0 & 0 & 0 & 0 & 0 & 0 \\
\hline 28 & 1 & 1 & 0 & 0 & 0 & 0 & 0 & 1 & 0 \\
\hline 29 & 1 & 0 & 0 & 0 & 1 & 1 & 0 & 0 & 0 \\
\hline 30 & 1 & 1 & 0 & 1 & 1 & 0 & 1 & 0 & 0 \\
\hline 31 & 0 & 1 & 0 & 0 & 0 & 1 & 0 & 0 & 0 \\
\hline Total & 26 & 22 & 4 & 3 & 15 & 7 & 8 & 6 & 4 \\
\hline
\end{tabular}

Dari format tabel 2 dapat dihitung untuk penentuan nilai support kandidat 1 itemset, penentuan nilai support kandidat 2 item set, penentuan nilai minimum confidence, penentuan association rules, yang di uraikan ke dalam tabel 3 .

Tabel 3. Hasil Support 1 itemset

\begin{tabular}{clcc}
\hline NO & \multicolumn{1}{c}{ Kategori Kertas } & Jumlah & Support \\
\hline 1 & Adog 45 gr 128 cm & 26 & $83 \%$ \\
2 & Adog 45 gr 138 cm & 22 & $70 \%$ \\
3 & Adog 45 gr 64 cm & 4 & $12 \%$ \\
4 & Adog 45 gr 69 cm & 3 & $9 \%$ \\
5 & 48.8 gr 114 cm & 15 & $48 \%$ \\
6 & 48.8 gr 152 cm & 7 & $22 \%$ \\
7 & 48.8 gr 76 cm & 6 & $25 \%$ \\
8 & Sp 60 gr 156 cm & 4 & $19 \%$ \\
9 & Sp 60 gr 78 cm & & $12 \%$ \\
\hline
\end{tabular}

Pada tabel 3 Support yang mempunyai ambang batas lebih dari $20 \%$ ada lima kertas yaitu adog $45 \mathrm{gr}$
$128 \mathrm{~cm}$, adog $45 \mathrm{gr} 138 \mathrm{~cm}, 48.8 \mathrm{gr} 114 \mathrm{~cm}, 48.8 \mathrm{gr} 152$ $\mathrm{cm}$, dan 48.8gr $76 \mathrm{~cm}$. 
Tabel 4. Hasil Support 2 Itemset

\begin{tabular}{|c|c|c|c|}
\hline $\mathrm{NO}$ & Kategori Kertas & Jumlah & Support \\
\hline 1 & Adog 45 gr $128 \mathrm{~cm}$, Adog 45 gr $138 \mathrm{~cm}$ & 19 & $61 \%$ \\
\hline 2 & Adog 45 gr $128 \mathrm{~cm}$, adog $45 \mathrm{gr} 64 \mathrm{~cm}$ & 3 & $9 \%$ \\
\hline 3 & Adog 45 gr $128 \mathrm{~cm}$, Adog 45 gr $69 \mathrm{~cm}$ & 3 & $9 \%$ \\
\hline 4 & Adog 45 gr $128 \mathrm{~cm}, 48.8$ gr $114 \mathrm{~cm}$ & 15 & $48 \%$ \\
\hline 5 & Adog 45 gr $128 \mathrm{~cm}, 48.8$ gr $152 \mathrm{~cm}$ & 6 & $19 \%$ \\
\hline 6 & Adog 45 gr $128 \mathrm{~cm}, 48.876 \mathrm{~cm}$ & 8 & $25 \%$ \\
\hline 7 & Adog 45 gr $128 \mathrm{~cm}$, Sp 60 gr $156 \mathrm{~cm}$ & 6 & $19 \%$ \\
\hline 8 & Adog 45 gr $128 \mathrm{~cm}$, Sp 60 gr $78 \mathrm{~cm}$ & 4 & $12 \%$ \\
\hline 9 & Adog 45 gr $138 \mathrm{~cm}$, adog $45 \mathrm{gr} 64 \mathrm{~cm}$ & 1 & $3 \%$ \\
\hline 10 & Adog 45 gr $138 \mathrm{~cm}$, Adog 45 gr $69 \mathrm{~cm}$ & 3 & $9 \%$ \\
\hline 11 & Adog 45 gr $138 \mathrm{~cm}, 48.8$ gr $114 \mathrm{~cm}$ & 11 & $35 \%$ \\
\hline 12 & Adog 45 gr $138 \mathrm{~cm}, 48.8$ gr $152 \mathrm{~cm}$ & 5 & $16 \%$ \\
\hline 13 & Adog $45 \mathrm{gr} 138 \mathrm{~cm}, 48.876 \mathrm{~cm}$ & 6 & $19 \%$ \\
\hline 14 & Adog 45 gr $138 \mathrm{~cm}$, Sp 60 gr $156 \mathrm{~cm}$ & 5 & $16 \%$ \\
\hline 15 & Adog 45 gr $138 \mathrm{~cm}$, Sp 60 gr $78 \mathrm{~cm}$ & 3 & $9 \%$ \\
\hline 16 & Adog 45 gr $64 \mathrm{~cm}$, Adog 45 gr $69 \mathrm{~cm}$ & 0 & $0 \%$ \\
\hline 17 & Adog 45 gr $64 \mathrm{~cm}, 48.8$ gr $114 \mathrm{~cm}$ & 2 & $6 \%$ \\
\hline 18 & Adog 45 gr $64 \mathrm{~cm}, 48.8$ gr $152 \mathrm{~cm}$ & 0 & $0 \%$ \\
\hline 19 & Adog 45 gr $64 \mathrm{~cm}, 48.876 \mathrm{~cm}$ & 0 & $0 \%$ \\
\hline 20 & Adog 45 gr $64 \mathrm{~cm}$, Sp 60 gr $156 \mathrm{~cm}$ & 0 & $0 \%$ \\
\hline 21 & Adog 45 gr $64 \mathrm{~cm}$, Sp 60 gr $78 \mathrm{~cm}$ & 0 & $0 \%$ \\
\hline 22 & Adog 45 gr $69 \mathrm{~cm}, 48.8$ gr $114 \mathrm{~cm}$ & 2 & $6 \%$ \\
\hline 23 & Adog 45 gr $69 \mathrm{~cm}, 48.8$ gr $152 \mathrm{~cm}$ & 2 & $6 \%$ \\
\hline 24 & Adog 45 gr $69 \mathrm{~cm}, 48.876 \mathrm{~cm}$ & 1 & $3 \%$ \\
\hline 25 & Adog 45 gr $69 \mathrm{~cm}, \mathrm{Sp} 60$ gr $156 \mathrm{~cm}$ & 0 & $0 \%$ \\
\hline 26 & Adog 45 gr $69 \mathrm{~cm}$, Sp 60 gr $78 \mathrm{~cm}$ & 0 & $0 \%$ \\
\hline 27 & $48.8 \mathrm{gr} 114 \mathrm{~cm}, 48.8 \mathrm{gr} 152 \mathrm{~cm}$ & 4 & $12 \%$ \\
\hline 28 & $48.8 \mathrm{gr} 114 \mathrm{~cm}, 48.876 \mathrm{~cm}$ & 6 & $19 \%$ \\
\hline 29 & 48.8 gr $114 \mathrm{~cm}, \mathrm{Sp} 60$ gr $156 \mathrm{~cm}$ & 3 & $9 \%$ \\
\hline 30 & 48.8 gr $114 \mathrm{~cm}, \mathrm{Sp} 60 \mathrm{gr} 78 \mathrm{~cm}$ & 2 & $6 \%$ \\
\hline 31 & $48.8 \mathrm{gr} 152 \mathrm{~cm}, 48.876 \mathrm{~cm}$ & 0 & $0 \%$ \\
\hline 32 & 48.8 gr $152 \mathrm{~cm}, \mathrm{Sp} 60$ gr $156 \mathrm{~cm}$ & 0 & $0 \%$ \\
\hline 33 & 48.8 gr $152 \mathrm{~cm}, \mathrm{Sp} 60 \mathrm{gr} 78 \mathrm{~cm}$ & 0 & $0 \%$ \\
\hline 34 & 48.8 gr $76 \mathrm{~cm}, \mathrm{Sp} 60$ gr $156 \mathrm{~cm}$ & 1 & $3 \%$ \\
\hline 35 & $48.8 \mathrm{gr} 76 \mathrm{~cm}, \mathrm{Sp} 60 \mathrm{gr} 78 \mathrm{~cm}$ & 1 & $3 \%$ \\
\hline 36 & Sp 60 gr $156 \mathrm{~cm}, \mathrm{Sp} 60 \mathrm{gr} 78 \mathrm{~cm}$ & 4 & $12 \%$ \\
\hline
\end{tabular}

Pada tabel 4 terlihat support yang melebihi ambang batas $20 \%$ ada empat kategori kertas yaitu Adog 45gr $128 \mathrm{~cm}$ dan Adog $45 \mathrm{gr} 138 \mathrm{~cm}$, Adog $45 \mathrm{gr} 128 \mathrm{~cm}$ dan
$48.8 \mathrm{gr} 114 \mathrm{~cm}$, Adog $45 \mathrm{gr} 128 \mathrm{~cm}$ dan $48.8 \mathrm{gr} 76 \mathrm{~cm}$, Adog 45 gr $138 \mathrm{~cm}$ dan $48.8 \mathrm{gr} 114 \mathrm{~cm}$.

Tabel 5. Hasil Minimum Confidence 2 Itemset

\begin{tabular}{cccc}
\hline NO & Kategori Kertas & Jumlah & Confidence \\
\hline 1 & Adog 45 gr $128 \mathrm{~cm}$, Adog $45 \mathrm{gr} 138 \mathrm{~cm}$ & 19 & $73 \%$ \\
2 & Adog $45 \mathrm{gr} 128 \mathrm{~cm}, 48.8$ gr $114 \mathrm{~cm}$ & 15 & $57 \%$ \\
3 & Adog 45 gr $128 \mathrm{~cm}, 48.8$ gr $76 \mathrm{~cm}$ & 8 & $30 \%$ \\
4 & Adog 45 gr $138 \mathrm{~cm}, 48.8$ gr $114 \mathrm{~cm}$ & 11 & $50 \%$ \\
\hline
\end{tabular}

Tabel 6. Hasil Association Rules

\begin{tabular}{ccccc}
\hline NO & Kategori Kertas & Jumlah & Support & Confidence \\
\hline 1 & Adog 45 gr $128 \mathrm{~cm}$, Adog $45 \mathrm{gr} 138 \mathrm{~cm}$ & 19 & $61 \%$ & $73 \%$ \\
2 & Adog 45 gr $128 \mathrm{~cm}, 48.8 \mathrm{gr} 114 \mathrm{~cm}$ & 15 & $48 \%$ & $57 \%$ \\
3 & Adog 45 gr $128 \mathrm{~cm}, 48.8 \mathrm{gr} 76 \mathrm{~cm}$ & 8 & $25 \%$ & $30 \%$ \\
4 & Adog 45 gr $138 \mathrm{~cm}, 48.8 \mathrm{gr} 114 \mathrm{~cm}$ & 11 & $35 \%$ & $50 \%$ \\
\hline
\end{tabular}


Hasil dengan menggunakan software RapidMiner tahapan proses untuk association rules ditampilkan pada gambar 2.gambar 3 dan gambar 4.

\begin{tabular}{|l|l|l|l|l|}
\hline No. & Premises & Conclusion & Support & Confidence \\
\hline 2 & $48.8 \mathrm{gr} 114 \mathrm{~cm}$ & Adog $45 \mathrm{gr} 128 \mathrm{~cm}$ & 0.484 & 1 \\
\hline 3 & $48.8 \mathrm{gr} 76 \mathrm{~cm}$ & Adog $45 \mathrm{gr} 128 \mathrm{~cm}$ & 0.258 & 1 \\
\hline 4 & Adog $45 \mathrm{gr} 138 \mathrm{~cm}, 48.8 \mathrm{gr} 114 \mathrm{~cm}$ & Adog $45 \mathrm{gr} 128 \mathrm{~cm}$ & 0.355 & 1 \\
\hline
\end{tabular}

Gambar 2. Support dan Confidence menggunakan RapidMiner dari data kertas

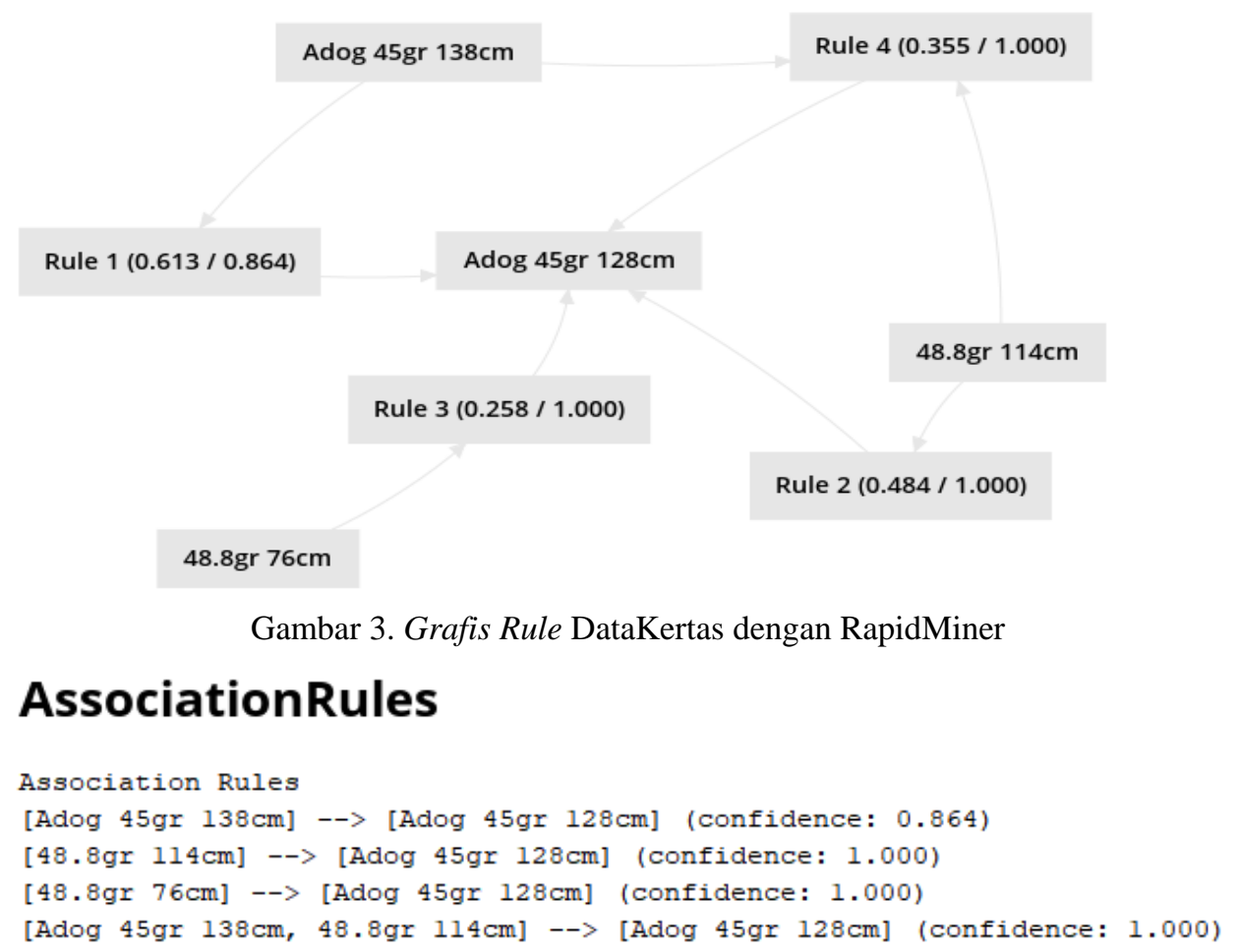

Gambar 4. Association Rule dari Rapid Miner

Dari hasil analisis data diatas, pola pemakaian kertas paling banyak terdapat pada kertas Adog 45gr $128 \mathrm{~cm}$ dan Adog $45 \mathrm{gr} 138 \mathrm{~cm}$ dengan persentase pemakaian mencapai $73 \%$. Oleh karena itu PT. Aliansi Temprina Nyata Grafika harus mempunyai stok minimal untuk kertas Adog $45 \mathrm{gr} 128 \mathrm{~cm}$ sebanyak 18 roll dan kertas Adog $45 \mathrm{gr} 138 \mathrm{~cm}$ sebanyak 16 roll untuk memenuhi banyaknya permintaan dan mencegah terjadinya kekurangan stok kertas dengan kategori tersebut yang akan diprediksikan terjadi pada bulan berikutnya. Untuk hipotensinya memakai yang $\mathrm{H}_{1}=$ Pemesanan bahan baku yang tepat, berpengaruh secara signifikan terhadap stok kebutuhan bahan baku.

\section{KESIMPULAN}

Berdasarkan hasil penelitian yang telah dilakukan dengan metode association dalam menentukan persediaan bahan baku kertas berdasarkan pemakaian pada PT. Aliansi Temprina Nyata Grafika maka dapat disimpulkan bahwa penelitian ini berhasil menganalisa data pemakaian kertas untuk mengetahui kecenderungan kertas-kertas mana saja yang sering terpakai secara bersamaan sehingga dapat melihat dan menentukan pola persediaan stok kertas berdasarkan pemakaian pada PT. Aliansi Temprina Nyata Grafika agar dijadikan sebagai acuan untuk stok kertas pada bulan berikutnya dan dapat mengatasi keterbatasan tempat penyimpanan kertas karena sudah mengetahui stok yang dibutuhkan. 


\section{REFERENSI}

Aris Gkoulalas-Divanis, V. S. V. (2010). Association Rule Hiding for Data Mining.

Asa Verano, D. (2016). Assosiasi Rules Dan Moving Average Untuk Memprediksi Persediaan Bahan Baku Produksi. ANNUAL RESEARCH SEMINAR.

Elisa, E. (2018). Market Basket Analysis Pada Mini Market Ayu Dengan Algoritma Apriori. Jurnal RESTI (Rekayasa Sistem Dan Teknologi Informasi). https://doi.org/10.29207/resti.v2i2.280

Haryana, A., Rochman, A., \& Setyaningsih, A. (2017). Perancangan sistem informasi perencanaan dan pengendalian bahan baku pada home industri. Jurnal Sisfotek Global.

Irawan, P. A., \& Syaicu, A. (2017). Pengendalian Persediaan Bahan Baku Dengan Metode Material Requirement Planning (Mrp) Pada Pt. Semen Indonesia (Persero), Tbk. Journal Knowledge Industrial Engineering.

Junaidi, A. (2019). Implementasi Algoritma Apriori dan FP-Growth Untuk Menentukan Persediaan Barang. Jurnal Sisfokom (Sistem Informasi Dan Komputer). https://doi.org/10.32736/sisfokom.v8i1.604
Kadafi, M. (2019). Penerapan Algoritma FPGROWTH untuk Menemukan Pola Peminjaman Buku Perpustakaan UIN Raden Fatah Palembang. MATICS. https://doi.org/10.18860/mat.v10i2.5628

Nisbet, R., Miner, G., \& Yale, K. (2017). Handbook of statistical analysis and data mining applications. In Handbook of Statistical Analysis and Data Mining Applications. https://doi.org/10.1016/c2012-0-06451-4

Wahyuning, R., Kom, A. M., Kom, L. S. M., Wijaya, H., \& Informatika, T. (2017). Penerapan Association Rule Pada Data Persediaan Bahan Baku Di Pro Ab Chicken Jambi. 43-48.

Witten, I. H., Frank, E., Hall, M. A., \& Pal, C. J. (2016). Data Mining: Practical Machine Learning Tools and Techniques. In Data Mining: Practical Machine Learning Tools and Techniques. https://doi.org/10.1016/c2009-0-19715-5

Yang, X.-S. (2019). Introduction to Algorithms for Data Mining and Machine Learning. 